\title{
Management of infections in the immunocompromised child: General principles
}

\author{
Upton D. Allen*
}

\begin{abstract}
Infections represent an ongoing challenge for immunocompromised patients. Children are particularly vulnerable because of several age-related issues that relate in part to immune prematurity. This review addresses the challenges in managing infections among immunocompromised children and highlights several general principles that guide management.
\end{abstract}

Statement of novelty: This work provides important guidance to clinicians who are involved in the management of pediatric patients with an ever-expanding spectrum of immunocompromising disorders.

\section{Introduction}

There is an ever-expanding list of disorders that can compromise the immune systems of children, making them susceptible to a variety of infections. These disorders may be the result of inborn errors of immunity or acquired deficiencies. In each of these categories, infections remain an important cause of morbidity and mortality among immunocompromised children (Soler-Palacin et al. 2007; Fried and Bonilla 2009; Jyonouchi et al. 2009; Adeli and Buckley 2010; Yin et al. 2011; Subbarayan et al. 2011). The consequences of these infections vary depending on several factors, including the nature and severity of the immune deficits and the virulence of the organisms involved. In this regard, several factors may act separately or synergistically to alter the host's immune system, thereby increasing the risk of infection.

An important first step in the management of infections resulting from these immune deficits is an appreciation of the nature of the deficits, the magnitude of the increased risk of infections, and the likely pathogens that would cause infections. In this review, several general concepts relating to the risk of infections in immunocompromised children will be discussed, because of their importance in the prevention and management of infections among immunocompromised patients in general. These concepts include the effects of treatments and disease on the host's immune defenses, the concept of the net state of immunosuppression, the definition of infection versus disease states, primary versus secondary versus. first episode non-primary infections, pre-emptive treatment versus prophylaxis versus treatment of established disease and the concept of induction and maintenance therapy. In addition, pediatric-specific challenges are addressed.

\section{General Concepts}

\section{The effects of treatments and disease states on the host's immune defenses}

Treatments and disease states can have variable effects on the immune system, which is broadly divided into innate and adaptive immune response
Professor of Paediatrics, Hospital for Sick Children, University of Toronto, Toronto, ON
Submitted 28 June 2016

Accepted 10 August 2016

Available online 12 August 2016

LymphoSign Journal 3:87-98 (2016)

dx.doi.org/10.14785/lymphosign-2016-0007 
categories (Janeway et al. 2001). The innate response is always on, whereas the adaptive response is pathogen-specific and is induced. The latter involves humoral or cell-mediated immune responses. The former consists of several components, such as anatomic barriers, clearance mechanisms (phagocytosis), physiologic variables $(\mathrm{pH}$, temperature, iron-binding, proteins, enzymatic proteins, chemical defenses (superoxide and nitric oxide), and antimicrobial peptides (defensins).

Thus, in addition to congenital immunodeficiency states, the host's immune system and the susceptibility to infections may be affected by several factors that act singly or in combination to influence the following (Parkin and Cohen 2001): skin and mucosal barrier, nutritional status, microbial flora, reticuloendothelial system, phagocytic defenses, and humoral and cellular immunity.

The mucosal immune system is an integral component of the defense mechanism (Montilla et al. 2004). The skin, mucosal membrane surfaces, as well as the peritoneum and pleura all provide vital protection against infectious diseases. Several features of the skin provide an effective defense against infection. It provides a physical barrier that protects deeper tissues from infection. Keratin creates a tough and waterresistant barrier. The epithelial cells of the skin are constantly being replaced with the sloughing off of the outer layer and any contamination. The low $\mathrm{pH}$ of the skin as well as the presence of sebaceous glands inhibit the growth of several microorganisms. Finally, the skin is colonized by normal flora that compete with other more pathogenic organisms for space and nutrients. The consequences of breaches to the barrier are seen in patients with burns, for example. Such patients are at high risk of developing serious infections. In addition, the presence of intravascular catheters or related devices provide a short-circuit that organisms can use to bypass the defensive barrier provided by the skin.

The effect of damage to the mucosal barrier is illustrated by what happens in patients who have received chemotherapeutic agents that alter the mucosal barrier of the gastrointestinal (GI) tract. Such individuals are at an increased risk of infections by organisms that would ordinarily be colonizers of their GI tracts (Sonis et al. 2001; Stokman et al. 2003; Vera-Llonch et al. 2006; Napenas et al. 2007). Such organisms include enteric gram-negative bacteria that may cross a damaged mucosa into the bloodstream, resulting in serious infections. This is seen in cancer patients with severe mucositis, which puts them at risk of infections from the microbial flora that span the full length of the GI tract. Indeed, alterations in the microbial flora by antimicrobial agents also affect risks and outcomes from infections. The use of these agents may cause selective antimicrobial pressure that facilitates the emergence of antimicrobial resistance as well as the overgrowth of certain organisms. This is the case with Clostridium difficle infection that results from the elimination of gut commensals by antimicrobials, thereby allowing the overgrowth of Clostridium difficile.

The relationship between susceptibility to infections and nutritional deficiency is well-established. Such deficiencies might facilitate infections in several ways including, but not limited to, the breaking down of the skin and mucosal barriers as well as the absence of essential micronutrients. Indeed, malnutrition is regarded as the most common cause of immunodeficiency worldwide, affecting all age groups, but notably infants and young children. Among the immunologic abnormalities that have been attributed to under-nutrition are diminished $\mathrm{T}$-cell help in immune responses dependent on mature CD4 cells, delayed antibody responses to specific antigens, depressed mucosal secretory IgA and the associated antibody response to infections, impaired complement activation, impaired opsonic activity, and thymic atrophy (Katona and Katona-Apte 2008). In addition to nutritional deficiency, the use of non-enteral nutrition may be associated with impaired mucosal immunity (Beisel 1996).

Chemotherapeutic agents are well-known to be one of the major causes of immunodeficiency because of their effects on several aspects of the immune system. The effects may result in impaired function of the reticuloendothelial system and phagocytic defenses as well as resulting in humoral and cellular defects. The selectivity and severity of these defects depend on the nature of the specific agents used. Such agents may be associated with an increased likelihood of particular opportunistic infections. For example, the use of anti$\mathrm{T}$-cell globulins may result is susceptibility to herpes group viral infections, such as cytomegalovirus (CMV) and Epstein-Barr virus infections (EBV) (Allen and Preiksaitis 2013; Kotton et al. 2013). 


\section{The net state of immunosuppression}

In clinical practice, it would be ideal to try to quantify the degree of immunosuppression in relation to the intensity and type of immunosuppressive agents that are used. However, in most patients, the final determinant of the magnitude of the risk of infection is the net state of immunosuppression, which takes into account unmeasurable or unrecognized factors that contribute to immunosuppression. An example is the cancer patient who gets a cytomegalovirus infection which in turn contributes to further immunosuppression and an increased risk of secondary opportunistic infections, such as fungal infections. Thus, it is important to be aware of factors that might contribute to the net state of immunosuppression among patients who are known to be immunocompromised (Fernandez-Ruiz et al. 2014).

\section{Definition of infection versus disease states and related issues}

In the management of infections in immunocompromised patients, it is important to recognize the difference between infection and disease. In such patients, it is not unusual to treat infection pre-emptively prior to the onset of disease. Using CMV as an example, infection is defined as the demonstration of CMV replication without evidence of symptoms or end-organ disease (Ljungman et al. 2002). Disease requires the demonstration of CMV infection plus attributable symptoms. In this context, using organ transplant patients as an example, patients at risk of CMV disease posttransplantation are often followed with molecular tests (e.g., polymerase chain reaction) to detect CMV infection in the peripheral blood prior to the onset of disease. The detection of a positive test may result in the need for treatment with antiviral agents to prevent disease. This approach is referred to as "pre-emptive treatment" as a strategy to prevent disease. This is not to be confused with the treatment of disease, as with pre-emptive treatment there is no confirmed disease. An alternative strategy would be prophylaxis, which would entail giving antivirals to at-risk patients shortly after transplantation without monitoring or waiting on the resulting of monitoring.

The concept of pre-emptive treatment, as defined above, is often modified and used in various settings where immunocompromised patients are managed (Cordonnier et al. 2009). It is separate from the empiric treatment of disease, where one treats a particular disease based on the index of clinical suspicion while awaiting laboratory confirmation.

Another important concept in the management of infections in immunocompromised patients relates to primary versus secondary versus first episode nonprimary infections, notably those due to herpes viruses. Primary infections occur in patients who were previously non-immune to all strains of a particular infection (e.g., CMV). Secondary infections result from reactivation of latent infections. A third category is that of first episode non-primary infections. This is best documented for herpes simplex infections in normal hosts, where infection can occur with a new viral strain in the setting where infection has already occurred with another strain (James and Kimberlin 2015). For example, the patient who is known to be seropositive of Herpes simplex type 2 may get infected with type 1 and may have the benefit of some immune cross protection.

\section{Concept of induction and maintenance therapy}

In the management of infections in immunocompromised patients, it is often necessary to have a prolonged period of antimicrobial therapy after an initial period of more aggressive therapy (Saag et al. 2000). This approach has been the cornerstone of the management of tuberculosis for decades and is widely used in oncology where the initial period of more intensive treatment is often referred to as induction therapy, which is then followed by a maintenance phase (American Thoracic Society 2005). The necessity for a maintenance phase is related to the nature of the infecting organism and the immune competence of the host. While the concept of induction and maintenance may apply to infections in normal hosts, many of the organisms that result in the need for this approach typically are opportunistic pathogens causing disease in the immunocompromised. Examples of these infections include the following: tuberculosis, central nervous system (CNS) cryptococcal infection, CNS toxoplasmosis, and cytomegalovirus disease.

\section{Pediatric-specific challenges}

The immunocompromised infant or child may be at a greater risk of acquiring specific infections compared with their adult counterparts. One reason for this is that there are infections that are known to be more prevalent 
in younger age groups. An example is respiratory viral diseases such as respiratory syncytial virus illness (Hall et al. 2009). In these children, risk is related to their age group regardless of immune competence. However, on top of this, children who are immunocompromised are at risk of having more severe illnesses and poorer outcomes compared with those who are not immunocompromised.

Another challenge faced by some children relates to the increased likelihood of primary infections. For example, adult organ transplant recipients are more likely to be partially immune to some infections, such as CMV and EBV, whereas their pediatric counterparts are not. Primary infections typically are associated with more severe illnesses because of no preexisting host immunity.

Compared with adults, young children are less likely to have received their full series of vaccines and generally tend to be at a greater risk of vaccine-preventable diseases after the onset of immunosuppression.

\section{Clinical Clues to Specific Immunologic Defects}

In the management of infections in the immunocompromised host, there are clinical clues that might provide indications of specific immune deficits. Early identification of these infections is important in improving outcomes. An extensive review of these infections is beyond the scope of this review. In brief, patients with granulocytopenia may present with invasive bacterial diseases or lesions such as hepatic or perianal abscesses (Lejkowski et al. 2003). In addition, patients with granulocyte killing defects are prone to having deep-seated abscesses, recurrent skin abscesses, suppurative lymphadenitis, invasive pulmonary fungal infections, and recurrent gingivitis (Lublin et al. 2002). Similarly, B-cell related defects may be associated with various infections, including invasive bacterial infections, recurrent respiratory tract infections, among other infections (Lin and Kaliner 2014). T-cell defects are often associated with severe life-threatening infections depending on the degree of severity of the defect (Edgar 2008). Such infections include herpes group viral infections, Pneumocystis jiroveci infection, fungal infections, and mycobacterial infections. Complement deficiency (C3, C6, C7, or C8), is associated with meningococcal sepsis or meningitis as well as disseminated gonococcal infection, whereas $\mathrm{C} 3$ deficiency has been associated with invasive bacterial sepsis due to encapsulated organisms (Ram et al. 2010). With respect to the above, it is well established that normal hosts might also have severe illnesses due to these organisms, with some exceptions. For example, the occurrence of Pneumocystis jiroveci infection is consistent with an immune deficit. Similarly, recurrent herpes zoster or disseminated mycobacterial infections would not be expected in an immunocompetent child.

\section{Principles of Management of Selected Infections and Clinical Syndromes}

\section{Vaccine preventable diseases}

The immunocompromised host is at risk of severe outcomes from several vaccine-preventable diseases. The magnitude of this risk depends on the nature of the immune deficit. Among the various infectious diseases, invasive pneumococcal disease deserves special mention since the pneumococcus is such an important cause of bacteremia, pneumonia, and meningitis in children worldwide (Kucharski et al. 2016). The most important step in management is prevention, of which the current pneumococcal vaccines have a pivotal role. While the immune responses might be suboptimal, depending on the nature of the immune deficit, it is important that clinicians ensure that immunocompromised children are adequately vaccinated against pneumococcus. Typically, this involves a combination of the 13-valent pneumococcal conjugate and the 23 -valent polysaccharide vaccines given 8 weeks apart, with the conjugate vaccine being given first (American Academy of Pediatrics 2015a). The 23-valent vaccine should not be given to children less than 2 years of age because of their inability to mount an adequate immune response to the pneumococcal polysaccharide antigen. This is because the immune response to the polysaccharide is T-cell independent and in humans this response only develops after the age of 2 years (Rijkers et al. 1998).

In the above regard, vaccines play an important role in preventing infections in the immunocompromised host. Prevention can be achieved by a combination of strategies. Besides vaccination of the immunocompromised patient (in whom immune responses might be 
suboptimal), there is a recognition of the importance of the "cocoon strategy" that is widely used in protecting susceptible patients from specific vaccine-preventable diseases (Forsyth et al. 2015). In the context of immunocompromised patients, one vaccinates parents, caregivers, and other close contacts, which provides indirect protection by preventing disease in those in close proximity to the immunocompromised person. Examples of this type of strategy are the pertussis, varicella, and measles vaccination strategies for family members of immunocompromised children. Table 1 shows a list of common vaccines and which ones can be safely used in the immunocompromised host.

Information relating to detailed management is beyond the scope of this review. However, there are some general principles that are relevant. First, in considering the cause of the infection, it is important to first consider the causes of that syndrome in the immunocompetent subject; second, consider the nature of the immune deficit and the specific pathogens to which the host is vulnerable; third, consider the choice of empiric antimicrobial therapy; and lastly definitive treatment once a specific organism has been demonstrated. Table 2 shows suggested antimicrobial agents for selected pathogens or clinical scenarios in the immunocompromised host.

\section{Respiratory viral infections}

Immunocompromised patients are at risk of serious outcomes from respiratory viruses (Ison and Hayden 2002; Englund et al. 2011). The spectrum of viruses include but are not limited to respiratory syncytial virus (RSV), influenza viruses, parainfluenza viruses, adenovirus, human metapneumovirus, rhinovirus, enteroviruses, coronavirus, and bocavirus. Outcomes depend on several factors. In this regard, the severity of illness will vary depending on the nature of the patient population as well as the specific viral pathogens involved. For example, in children, recipients of allogeneic hematopoietic stem cell transplants and infants with severe combined immunodeficiency are among those that typically are at risk of the most severe outcomes. For some of these children, the recovery phase of illness

Table 1: List of common vaccines and their relative safety in immunocompromised hosts.

\begin{tabular}{|c|c|c|}
\hline Vaccine & $\begin{array}{l}\text { Inactivated }(\mathrm{I}) / \mathrm{live} \\
\text { attenuated }(\mathrm{LA})\end{array}$ & $\begin{array}{c}\text { Safe for } \\
\text { immunocompromised host }\end{array}$ \\
\hline \multicolumn{3}{|l|}{ Routine vaccines } \\
\hline Diphtheria & I & Yes \\
\hline Pertussis & I & Yes \\
\hline Tetanus & I & Yes \\
\hline Inactivated Polio vaccine & I & Yes \\
\hline H. influenzae $B$ (regardless of age) & I & Yes \\
\hline $\begin{array}{l}\text { S. pneumoniae (Conjugate PCV } \\
\text { 13/23-valent polysaccharide*) }\end{array}$ & 1 & Yes \\
\hline $\begin{array}{l}\text { N. meningitidis (Conjugate } \mathrm{C} \text { and } \\
\text { conjugate quadrivalent) }\end{array}$ & I & Yes \\
\hline \multirow{2}{*}{ Influenza } & I & Yes \\
\hline & LA & No \\
\hline Hepatitis B & 1 & Yes \\
\hline Hepatitis A & I & Yes \\
\hline Measles $^{\dagger}$ & LA & No \\
\hline Mumps $^{\dagger}$ & LA & No \\
\hline Rubella $^{\dagger}$ & LA & No \\
\hline Varicella $^{\dagger}$ & LA & No \\
\hline Rotavirus & LA & No \\
\hline Human papillomavirus & 1 & Yes \\
\hline \multicolumn{3}{|l|}{ Vaccines for special circumstances } \\
\hline BCG & LA & No \\
\hline Rabies & 1 & Yes \\
\hline
\end{tabular}


Table 2: Recommended treatment for selected infections or scenarios in the immunocompromised host.

\begin{tabular}{|c|c|c|c|}
\hline $\begin{array}{l}\text { Infection or clinical } \\
\text { scenario }\end{array}$ & Recommended treatment & Alternatives & Comments \\
\hline \multicolumn{4}{|l|}{ Invasive fungal diseases } \\
\hline $\begin{array}{l}\text { Invasive pulmonary } \\
\text { Aspergillosis }\end{array}$ & Voriconazole & $\begin{array}{l}\text { Lipid amphotericin, } \\
\text { echinocandins }\end{array}$ & $\begin{array}{l}\text { Need to confirm adequate blood levels of } \\
\text { voriconazole }\end{array}$ \\
\hline Invasive candidiasis & $\begin{array}{l}\text { Lipid amphotericin B or } \\
\text { amphotericin B } \\
\text { dexoycholate }\end{array}$ & $\begin{array}{l}\text { Fluconazole, } \\
\text { echinocandins* }\end{array}$ & $\begin{array}{l}\text { Fluconazole not appropriate until species } \\
\text { identified. Several factors influence choice } \\
\text { (e.g., echinocandins not for central nervous } \\
\text { system infection) }\end{array}$ \\
\hline $\begin{array}{l}\text { Pneumocystis jirovecci } \\
\text { pneumonia }\end{array}$ & TMP-SMX (IV) & Pentamidine (IV) & $\begin{array}{l}\text { Other agents in consultation with Infectious } \\
\text { diseases specialist }\end{array}$ \\
\hline \multicolumn{4}{|l|}{ Bacteremia } \\
\hline \multicolumn{4}{|l|}{ Enteric Gram-negative } \\
\hline S. aureus & Cloxacillin & $\begin{array}{l}\text { First generation } \\
\text { cephalosporins }\end{array}$ & $\begin{array}{l}\text { Vancomycin for methicillin-resistant } \\
\text { Staphylococcus aureus }\end{array}$ \\
\hline S. pneumoniae & $\begin{array}{l}\text { Penicillin non-susceptible: } \\
\text { cefotaxime or ceftriaxone } \\
\pm \text { vancomycin }\end{array}$ & $\begin{array}{l}\text { Penicillin susceptible: } \\
\text { penicillin }\end{array}$ & $\begin{array}{l}\text { Empiric treatment: assume penicillin non- } \\
\text { susceptible; regimen depends on focus of } \\
\text { infection; ceftriaxone + vancomycin for } \\
\text { meningitis or critically ill }\end{array}$ \\
\hline \multicolumn{4}{|l|}{ Viral infections } \\
\hline Varicella & Acyclovir & See comment & Agents other than acyclovir rarely needed \\
\hline $\begin{array}{l}\text { Influenza } A \text { and } B \\
\text { infection }\end{array}$ & Neuraminidase inhibitors & See comment & $\begin{array}{l}\text { Oseltamivir most often used; M2 inhibitors } \\
\text { inactive against influenza B }\end{array}$ \\
\hline Herpes simplex infection & Acyclovir & Valacyclovir & Agents other than acyclovir rarely needed \\
\hline Cytomeaglovirus & Ganciclovir & Foscarnet & Other agents in cases of resistance \\
\hline Epstein-Barr virus & Ganciclovir & Foscarnet & $\mathrm{n} / \mathrm{a}$ \\
\hline Adenoviral disease & Brincidofovir or Cidofovir & See comment & $\begin{array}{l}\text { Brincidofovir now favoured due to renal toxicity } \\
\text { with cidofovir. }\end{array}$ \\
\hline Respiratory syncytial virus & Ribavirin (aerosolized) & $\mathrm{n} / \mathrm{a}$ & $\mathrm{n} / \mathrm{a}$ \\
\hline \multicolumn{4}{|c|}{ Other infections or scenarios } \\
\hline Febrile neutropenic state & $\begin{array}{l}\text { Piperacillin-tazobactam }{ }^{\dagger} \text {; } \\
\text { carbapenem }\end{array}$ & $\begin{array}{l}\text { See comment; specific } \\
\text { indications for } \\
\text { vancomycin }^{\ddagger}\end{array}$ & Guided by susceptibility of local flora \\
\hline
\end{tabular}

${ }^{*}$ Echinocandins should be used with caution against Candida parapsilosis.

${ }^{\dagger}$ Must be guided by local antimicrobial susceptibility data.

${ }^{\ddagger}$ Indications for vancomycin include: hemodynamic instability or other evidence of severe sepsis, pneumonia, positive blood culture with Gram +ve bacteria, catheterrelated infection, skin or soft-tissue infection, methicillin-resistant Staphylococcus aureus, vancomycin-resistant enterococcus, penicillin-resistant pneumococcal colonization, severe mucositis.

can be prolonged and the virus may be shed in respiratory secretions for several months with periodic exacerbation in clinical illness (Lehners et al. 2016).

The pivotal step in the pathogenesis that relates to poorer outcomes is the progression from viral upper respiratory tract infection (URTI) to a lower respiratory tract infection (LRTI). Table 3 show a summary of the relative rates of progression from URTI to LRTI for different respiratory viruses and the associated mortality rates among stem cell transplant recipients (Renaud and Englund 2012). While the ranges of mortality rates overlap, there is a general trend toward higher mortality rates from adenovirus.
Table 3: Respiratory viral infections in HSCT patients: progression to lower tract disease and mortality.

\begin{tabular}{lcc}
\hline Viruses & $\begin{array}{c}\text { Progression to lower } \\
\text { respiratory tract } \\
\text { infection } \\
\text { (percentage range) }\end{array}$ & $\begin{array}{c}\text { Mortality due to } \\
\text { lower respiratory } \\
\text { tract infection } \\
\text { (percentage range) }\end{array}$ \\
\hline $\begin{array}{l}\text { Influenza } \\
\text { Respiratory } \\
\text { syncytial virus }\end{array}$ & $7-35$ & $15-28$ \\
$\begin{array}{l}\text { Parainfluenza virus } \\
\text { Human } \\
\text { metapneumovirus }\end{array}$ & $18-55$ & $7-33$ \\
Adenovirus & $13-43$ & $12-50$ \\
\hline Rhinovirus & $21-40$ & $33-40$ \\
Coronavirus & $22-25$ & $40-50$ \\
Bocavirus & $<5$ & - \\
\hline
\end{tabular}


Diagnostic methods for respiratory viruses have evolved significantly with the availability of multiple systems capable of detecting several viruses (El Kholy et al. 2016; Malhotra et al. 2016). A more challenging issue relates to specific treatment of viruses other than influenza, for which the neuraminidase inhibitors are available. This is illustrated in Table 4 with a list of respiratory viruses relative to the available treatment and prevention strategies. With respect to the issue of prevention, Table 4 shows that infection control is essential for all of these viruses. Indications exist for the use of the neuraminidase inhibitors in the prevention of influenza illness among high-risk groups, such as the immunocompromised host. A humanized mouse monoclonal antibody preparation (palivizumab) is available for the prevention of RSV, although data are limited outside of the setting of immunoprophylaxis for infants and children less than 2 years of age with prematurity, chronic lung disease, and hemodynamically significant heart disease (Meissner et al. 1999).

\section{Pneumonias in the immunocompromised}

Immunocompromised children are at risk of pneumonia due to opportunistic pathogens. The specific pathogens depend on the nature of the immune deficit. For example, risk factors for Pneumocystis jirovecci pneumonia (PJP) among leukemics include prolonged corticosteroid therapy (American Academy of Pediatrics 2015b; Shankar and Nania 2007). In addition, the level of CD4 count determines the likelihood of PJP among HIV/AIDS patients. Infants with severe combined immunodeficiency are among those who are known to be at risk of PJP. The spectrum of these opportunistic pathogens includes fungal (e.g., aspergillus) and viral infections (e.g., cytomegalovirus). However, other organisms include parasites, such as strongyloides and protozoa, such as toxoplasma. In addition to opportunistic pathogens, immunocompromised patients are generally more susceptible to pneumonias that occur in otherwise healthy children (e.g., pneumonia due to Streptococcus pneumoniae). Knowledge of the relationship between the specific immune deficits and the occurrence of particular pathogens is a first step in the management of pneumonias due to opportunistic pathogens.

In the approach to establishing the etiological agent, there are a number of important principles. First, the radiographic appearance may be atypical due to the inability of the host to mount an immune response of the type seen in non-immunocompromised patients. Second, the importance of early and accurate recognition of infectious agents cannot be over-emphasized, while always considering the possibility of non-infectious aetiologies; examples of the latter include engraftment syndrome (Spitzer 2001), radiation injury (Merril), drug induced injury (Byrd), idiopathic pneumonia syndrome (Shankar and Cohen 2001), transfusion-related acute lung injury (Silliman et al. 2005), ARDS due to extrapulmonary processes (ARDS Definition Task Force et al. 2012), and graft versus host disease in hematopoietic stem cell transplant recipients (Ferrara and Deeg 1991). Third, getting a microbiologic diagnosis is important in the management of patients. This allows for therapy to be more appropriately targeted, thereby improving the chances for better outcomes. This also potentially minimizes the risk of side-effects from using particular drugs empirically, yet not actually targeting the potential pathogen.

Treatment should be directed at the offending pathogen. Typically, if an etiologic agent has not been

Table 4: List of common respiratory viruses relative to the availability of treatment and prevention strategies.

\begin{tabular}{|c|c|c|c|c|c|}
\hline Virus & $\begin{array}{l}\text { Vaccines } \\
\text { available }\end{array}$ & $\begin{array}{l}\text { Infection control } \\
\text { effective }\end{array}$ & $\begin{array}{c}\text { Chemoprophylaxis } \\
\text { effective }\end{array}$ & $\begin{array}{c}\text { Immunoprophylaxis } \\
\text { effective }\end{array}$ & $\begin{array}{l}\text { Treatment } \\
\text { effective }\end{array}$ \\
\hline Influenza & +++++ & +++++ & +++++ & - & ++++ \\
\hline $\begin{array}{l}\text { Respiratory syncytial } \\
\text { virus }\end{array}$ & - & +++++ & - & +++++ & \pm \\
\hline Parainfluenza & - & +++++ & - & - & \pm \\
\hline $\begin{array}{l}\text { Human meta- } \\
\text { pneumovirus }\end{array}$ & - & +++++ & - & - & - \\
\hline Adenovirus & - & +++++ & - & - & \\
\hline Rhinovirus & - & +++++ & - & - & - \\
\hline Coronavirus & - & +++++ & - & - & - \\
\hline Bocavirus & - & +++++ & - & - & - \\
\hline
\end{tabular}


identified, empiric therapy should be initiated with broad spectrum antimicrobials that target the likely pathogen.

\section{Fever and neutropenia}

The febrile neutropenic state puts patients at risk of infection due to a spectrum of organisms (Chen et al. 2004; Ramphal 2004; Oliveira et al. 2007; Cattaneo et al. 2008; Freifeld et al. 2011). In this review, general principles relating to the management of the febrile neutropenic patient are discussed. Among these, enteric Gram-negative bacteria have traditionally been associated with potentially severe outcomes (Cattaneo et al. 2008). The list of potential organisms include but is not limited to the following: Coagulase-negative staphylococci; Staphylococcus aureus, including methicillin-resistant Staphylococcus aureus (MRSA); Enterococcus species, including vancomycin-resistant enterococci (VRE); viridans group streptococci; Streptococcus pneumoniae; Streptococcus pyogenes; Escherichia coli; Klebsiella species; Enterobacter species; Pseudomonas aeruginosa; Citrobacter species; Acinetobacter species; and Stenotrophomonas maltophilia.

The management of the febrile neutropenic patients can be divided into 4 steps that take into account the likelihood that specific pathogens are present at specific stages.
- $\quad$ The first step in management takes into account the need for broad spectrum empiric antibiotic coverage aimed at the likely organisms. In considering the choice of empiric therapy, it is necessary to take into account not only the specific organism (e.g., E. coli), but also whether the organism is susceptible to the available antimicrobials based on the susceptibility profiles of local flora.

- The second step involves reassessment of the patient at $48-72$ hours to determine if one should modify empiric therapy based on the clinical course of the patient. In addition, adjustments of the antimicrobials may need to be made anytime new microbiologic information becomes available.

- The third step relates to the management at 4-5 days in the patient who is persistently febrile. Such patients have been shown to be at risk of having invasive fungal disease. As such, a fungal evaluation would be indicated and consideration given to starting empiric antifungal therapy.

- The final step relates to making a decision regarding the duration of antimicrobial therapy. This decision is based on several factors, notably the extent of count recovery, the presence of fever and whether or not a specific organism has been identified.

Table 5: Selected organisms and the usual antimicrobials used for chemoprophylaxis.

\begin{tabular}{|c|c|c|}
\hline Targeted organisms & Antimicrobial agents & Key selected comments \\
\hline \multicolumn{3}{|l|}{ Fungal species } \\
\hline \multirow[t]{5}{*}{ Aspergillus species } & Itraconazole & $\begin{array}{l}\text { Oral available; drug levels variable; need to monitor drug levels in } \\
\text { children }\end{array}$ \\
\hline & Voriconazole & $\begin{array}{l}\text { Oral available; drugs levels variable; need to monitor drug levels in } \\
\text { children }\end{array}$ \\
\hline & Posaconazole & $\begin{array}{l}\text { Oral available; broad-spectrum, includes coverage against } \\
\text { zygomyces }\end{array}$ \\
\hline & Echinocandins & Parenteral; selected scenarios only \\
\hline & Ampotericin B products & $\begin{array}{l}\text { Parenteral; nephrotoxicity more likely with conventional } \\
\text { amphotericin B }\end{array}$ \\
\hline \multirow[t]{3}{*}{ Candida species } & Fluconazole & Oral available; deranged transaminases \\
\hline & Nystatin & Oral; typically, no significant major side-effects \\
\hline & Echinocandins & Parenteral; selected scenarios only \\
\hline Zygomyces species & Posaconazole & - \\
\hline \multicolumn{3}{|l|}{ Viral agents } \\
\hline Cytomegalovirus & Gancivlovir/valganciclovir & Valganciclovir, oral; neutropenia \\
\hline Epstein-Barr virus & Gancivlovir/valganciclovir & Neutropenia; effectiveness not well supported by evidence \\
\hline Herpes simplex virus & Acyclovir/valacyclovir & Oral available; nephrotoxicity (more with IV drug) \\
\hline Influenza viruses & Neuraminidase inhibitors & $\begin{array}{l}\text { Oral (oseltamivir); inhalational (zanamivir); antiviral drug } \\
\text { resistance, notably with prolonged therapy with oseltamivir }\end{array}$ \\
\hline \multicolumn{3}{|l|}{ Bacterial organisms } \\
\hline $\begin{array}{l}\text { Gram-positive and } \\
\text { Gram-negative organism }\end{array}$ & Selected antibacterial agents & $\begin{array}{l}\text { Antibacterial drug resistance, notably with prolonged therapy with } \\
\text { beta-lactams, quinolones, carbapenems }\end{array}$ \\
\hline
\end{tabular}




\section{Antimicrobial therapy for selected scenarios}

Some of the general principles relating to antimicrobial therapy and the selection of specific regimens are addressed in the text above and in Table 2. In general, in the management of immunocompromised hosts, antibiotics should be initiated as early as possible. In this regard, early initiation of therapy has been shown to relate to better outcomes (Kumar et al. 2006; Gaieski et al. 2010; Ferrer et al. 2014). The importance of broad empiric therapy, where appropriate, has been addressed above. While it is important that infections be treated for an appropriate duration of time, prolonged therapy poses problems relating to antimicrobial resistance. For this reason, the duration of therapy should be long enough to ensure adequate treatment of the particular infection, but should not be unnecessarily prolonged.

\section{Antimicrobial Chemoprophylaxis}

Antimicrobial chemoprophylaxis plays an important role in the prevention of infections in immunocompromised hosts. The specific agent that is used depends on the organism that is being prevented. In general, these agents should only be used when there is clear evidence that the benefits outweigh the risks. Among these risks, antimicrobial resistance is of major concern. While a comprehensive review of antimicrobial chemoprophylaxis or the myriad of clinical scenarios is beyond the scope of this article, a summary of commonly used prophylactic agents is listed in Table 5, with selected comments, including those relevant to the proper monitoring of patients on these agents prophylactically.

\section{Concluding Remarks}

Management of infections in the immunocompromised host is made challenging by several factors that relate to the nature of the host defect, the virulence of the infecting organisms, and in some cases the environment in which these patients are being managed. In this regard, a crucial first step in management is an adequate understanding of the host defect as this relates to the susceptibility to specific organisms and the ability of the host's immune system to act synergistically with antimicrobial agents to control the infection. This is an important concept that cannot be over-emphasized, given that the effectiveness of antimicrobials is enhanced in situations where benefit is also derived from some aspects of the host's immune system.

Finally, the prevention of infection is crucial. Vaccines, passive immunoprophylaxis, and antimicrobial chemoproproylaxis all have important roles to play depending on the infection that is being prevented.

\section{REFERENCES}

Adeli, M.M., and Buckley, R.H. 2010. Why newborn screening for severe combined immunodeficiency is essential: A case report. Pediatrics. 126(2):e465e469. PMID: 20603253. doi: 10.1542/peds.20093659.

Allen, U.D., and Green, M. 2010. Prevention and treatment of infectious complications after solid organ transplantation in children. Pediatr Clin North Am. 57(2):459-479. doi: doi:10.1016/j.pcl.2010.01.005.

Allen, U.D., and Preiksaitis, J.K., AST Infectious Diseases Community of Practice. 2013. Epstein-Barr virus and posttransplant lymphoproliferative disorder in solid organ transplantation. Am J Transplant. 13(Suppl 4):107-120. PMID: 23465004. doi: 10.1111/ ajt.12104.

American Academy of Pediatrics. 2015a. Pertussis (Pneumococcal Infections) in Kimberlin, D.W., Brady, M.T., Jackson, M.A., and Long, S.S., eds., Report of the Committee on Infectious Diseases, 30th ed., Elk Grove Village, IL: American Academy of Pediatrics, 626-638.

American Academy of Pediatrics. 2015b. Pertussis (Pneumocystis jirovecci Infections) in Kimberlin, D.W., Brady, M.T., Jackson, M.A., and Long, S.S., eds., Report of the Committee on Infectious Diseases, 30th ed., Elk Grove Village, IL: American Academy of Pediatrics, 638-644.

American Thoracic Society, Centers for Disease, Control and Prevention, and Infectious Diseases Society of America. 2005. American Thoracic Society/Centers for Disease Control and Prevention/ Infectious Diseases Society of America: Controlling tuberculosis in the United States. Am J Respir Crit Care Med. 172(9):1169-1227. PMID: 16249321. doi: $10.1164 / \mathrm{rccm} .2508001$.

ARDS Definition Task Force; Ranieri, V.M., Rubenfeld, G.D., Thompson, B.T., Ferguson, N.D., Caldwell, E., Fan, E., Camporota, L., and Slutsky, A.S. 2012. Acute respiratory distress syndrome: The Berlin Definition. JAMA. 307(23):2526-2533. PMID: 22797452. doi: 10.1001/jama.2012.5669. 
Beisel, W.R. 1996. Nutrition in pediatric HIV infection: Setting the research agenda. Nutrition and immune function: Overview. J Nutr. 126(10 Suppl):2611S2615S. PMID: 8861922.

Byrd, R.P. 2015. Drug-Induced pulmonary toxicity. Available from http://emedicine.medscape.com/ article/1343451-overview.

Cattaneo, C., Quaresmini, G., Casari, S., Capucci, M.A., Micheletti, M., Borlenghi, E., Signorini, L., Re, A., Carosi, G., and Rossi, G. 2008. Recent changes in bacterial epidemiology and the emergence of fluoroquinolone-resistant Escherichia coli among patients with haematological malignancies: Results of a prospective study on 823 patients at a single institution. J Antimicrob Chemother. 61(3):721-728. PMID: 18218645. doi: 10.1093/jac/dkm514.

Chen, C.Y., Tang, J.L., Hsueh, P.R., Yao, M., Huang, S.Y., Chen, Y.C., Chen, Y.C., Shen, M.C., Wang, C.H., Tsai, W., Chang, S.C., Tien, H.F., and Luh, K.T. 2004. Trends and antimicrobial resistance of pathogens causing bloodstream infections among febrile neutropenic adults with hematological malignancy. J Formos Med Assoc. 103(7):526-532. PMID: 15318274.

Cordonnier, C., Pautas, C., Maury, S., Vekhoff, A., Farhat, H., Suarez, F., Dhedin, N., Isnard, F., Ades, L., Kuhnowski, F., Foulet, F., Kuentz, M., Maison, P., Bretagne, S., and Schwarzinger, M. 2009. Empirical versus preemptive antifungal therapy for high-risk, febrile, neutropenic patients: A randomized, controlled trial. Clin Infect Dis. 48(8):10421051. PMID: 19281327. doi: 10.1086/597395.

Edgar, J.D. 2008. T cell immunodeficiency. J Clin Pathol. 61(9):988-993. PMID: 18755723. doi: 10.1136/jcp.2007.051144.

El Kholy, A.A., Mostafa, N.A., Ali, A.A., Soliman, M.M., El-Sherbini, S.A., Ismail, R.I., El Basha, N., Magdy, R.I., El Rifai, N., and Hamed, D.H. 2016. The use of multiplex PCR for the diagnosis of viral severe acute respiratory infection in children: A high rate of co-detection during the winter season. Eur J Clin Microbiol Infect Dis. PMID: 27287764. doi: 10.1007/ s10096-016-2698-5.

Englund, J., Feuchtinger, T., and Ljungman, P. 2011. Viral infections in immunocompromised patients. Biol Blood Marrow Transplant. 17(1 Suppl):S2-S5. PMID: 21195305. doi: 10.1016/j.bbmt.2010.11.008.

Fernandez-Ruiz, M., Kumar, D., and Humar, A. 2014. Clinical immune-monitoring strategies for predicting infection risk in solid organ transplantation. Clin
Transl Immunology. 3(2):e12. PMID: 25505960. doi: 10.1038/cti.2014.3.

Ferrara, J.L., and Deeg, H.J. 1991. Graft-versus-host disease. N Engl J Med. 324(10):667-674. PMID: 1994250. doi: 10.1056/NEJM199103073241005.

Ferrer, R., Martin-Loeches, I., Phillips, G., Osborn, T.M., Townsend, S., Dellinger, R.P., Artigas, A., Schorr, C., and Levy, M.M. 2014. Empiric antibiotic treatment reduces mortality in severe sepsis and septic shock from the first hour: Results from a guideline-based performance improvement program. Crit Care Med. 42(8):1749-1755. PMID: 24717459. doi: 10.1097/ CCM.0000000000000330.

Forsyth, K., Plotkin, S., Tan, T., and Wirsing von Konig, C.H. 2015. Strategies to decrease pertussis transmission to infants. Pediatrics. 135(6):e1475-e1482. PMID: 25963002. doi: 10.1542/peds.2014-3925.

Freifeld, A.G., Bow, E.J., Sepkowitz, K.A., Boeckh, M.J., Ito, J.I., Mullen, C.A., Raad, II, Rolston, K.V., Young, J.A., Wingard, J.R., and Infectious Diseases Society of America. 2011. Clinical practice guideline for the use of antimicrobial agents in neutropenic patients with cancer: 2010 update by the Infectious Diseases Society of America. Clin Infect Dis. 52(4):e56-e93. PMID: 21258094. doi: 10.1093/ cid/cir073.

Fried, A.J., and Bonilla, F.A. 2009. Pathogenesis, diagnosis, and management of primary antibody deficiencies and infections. Clin Microbiol Rev. 22(3):396-414. PMID: 19597006. doi: 10.1128/CMR. 00001-09.

Gaieski, D.F., Mikkelsen, M.E., Band, R.A., Pines, J.M., Massone, R., Furia, F.F., Shofer, F.S., and Goyal, M. 2010. Impact of time to antibiotics on survival in patients with severe sepsis or septic shock in whom early goal-directed therapy was initiated in the emergency department. Crit Care Med. 38(4):1045-1053. PMID: 20048677. doi: 10.1097/ CCM.0b013e3181cc4824.

Hall, C.B., Weinberg, G.A., Iwane, M.K., Blumkin, A.K., Edwards, K.M., Staat, M.A., Auinger, P., Griffin, M.R., Poehling, K.A., Erdman, D., Grijalva, C.G., Zhu, Y., and Szilagyi, P. 2009. The burden of respiratory syncytial virus infection in young children. $\mathrm{N}$ Engl J Med. 360(6):588-598. PMID: 19196675. doi: 10.1056/NEJMoa0804877.

Ison, M.G., and Hayden, F.G. 2002. Viral infections in immunocompromised patients: What's new with respiratory viruses? Curr Opin Infect Dis. 15(4):355367. PMID: 12130931. 
James, S.H., and Kimberlin, D.W. 2015. Neonatal Herpes Simplex Virus Infection. Infect Dis Clin North Am. 29(3):391-400. PMID: 26154662. doi: 10.1016/j.idc.2015.05.001.

Janeway, C.A., Jr, Travers, P., Walport, M., and Schlomchik, M. 2001. Immunobiology: The Immune System in Health and Disease. 5th Edition., New York: Garland Science.

Jyonouchi, S., McDonald-McGinn, D.M., Bale, S., Zackai, E.H., and Sullivan, K.E. 2009. CHARGE (coloboma, heart defect, atresia choanae, retarded growth and development, genital hypoplasia, ear anomalies/deafness) syndrome and chromosome 22q11.2 deletion syndrome: A comparison of immunologic and nonimmunologic phenotypic features. Pediatrics. 123(5):e871-e877. PMID: 19403480. doi: 10.1542/peds.2008-3400.

Katona, P., and Katona-Apte, J. 2008. The interaction between nutrition and infection. Clin Infect Dis. 46(10):1582-1588. PMID: 18419494. doi: 10.1086/ 587658.

Kotton, C.N., Kumar, D., Caliendo, A.M., Asberg, A., Chou, S., Danziger-Isakov, L., Humar, A., and Transplantation Society International CMV Consensus Group 2013. Updated international consensus guidelines on the management of cytomegalovirus in solid-organ transplantation. Transplantation. 96(4):333-360. PMID: 23896556. doi: 10.1097/ TP.0b013e31829df29d.

Kucharski, A.J., Eggo, R.M., Watson, C.H., Camacho, A., Funk, S., and Edmunds, W.J. 2016. Effectiveness of ring vaccination as control strategy for Ebola virus disease, Emerg Infect Dis. 22(1):105-108. PMID: 26691346. doi: 10.3201/eid2201.151410.

Kumar, A., Roberts, D., Wood, K.E., Light, B., Parrillo, J.E., Sharma, S., Suppes, R., Feinstein, D., Zanotti, S., Taiberg, L., Gurka, D., Kumar, A., and Cheang, M. 2006. Duration of hypotension before initiation of effective antimicrobial therapy is the critical determinant of survival in human septic shock. Crit Care Med. 34(6):1589-1596. PMID: 16625125. doi: 10.1097/01. CCM.0000217961.75225.E9.

Lehners, N., Tabatabai, J., Prifert, C., Wedde, M., Puthenparambil, J., Weissbrich, B., Biere, B., Schweiger, B., Egerer, G., and Schnitzler, P. 2016. Long-Term Shedding of Influenza Virus, Parainfluenza Virus, Respiratory Syncytial Virus and Nosocomial Epidemiology in Patients with Hematological Disorders. PLoS One. 11(2): e0148258. PMID: 26866481. doi: 10.1371/journal. pone. 0148258 .
Lejkowski, M., Maheshwari, A., Calhoun, D.A., Christensen, R.D., Skoda-Smith, S., and Dabrow, S. 2003. Persistent perianal abscess in early infancy as a presentation of autoimmune neutropenia. J Perinatol. 23(5):428-430. PMID: 12847542. doi: $10.1038 /$ sj.jp.7210952.

Lin, R.Y., and Kaliner, M.A. 2014. Hypogammglobulinemia. Available from http://emedicine. medscape.com/article/136471-overview.

Ljungman, P., Griffiths, P., and Paya, C. 2002. Definitions of cytomegalovirus infection and disease in transplant recipients. Clin Infect Dis. 34(8):10941097. PMID: 11914998 . doi: $10.1086 / 339329$.

Lublin, M., Bartlett, D.L., Danforth, D.N., Kauffman, H., Gallin, J.I., Malech, H.L., Shawker, T., Choyke, P., Kleiner, D.E., Schwartzentruber, D.J., Chang, R., DeCarlo, E.S., and Holland, S.M. 2002. Hepatic abscess in patients with chronic granulomatous disease. Ann Surg. 235(3):383-391. PMID: 11882760.

Malhotra, B., Swamy, M.A., Reddy, P.V., Kumar, N., and Tiwari, J.K. 2016. Evaluation of custom multiplex real-time RT-PCR in comparison to fast-track diagnostics respiratory 21 pathogens kit for detection of multiple respiratory viruses. Virol J. 13:91. PMID: 27267595. doi: 10.1186/s12985-016-0549-8.

Meissner, H.C., Welliver, R.C., Chartrand, S.A., Law, B.J., Weisman, L.E., Dorkin, H.L., and Rodriguez, W.J. 1999. Immunoprophylaxis with palivizumab, a humanized respiratory syncytial virus monoclonal antibody, for prevention of respiratory syncytial virus infection in high risk infants: A consensus opinion. Pediatr Infect Dis J. 18(3):223-231. PMID: 10093942.

Merril, W.W. 2016. Radiation-induced lung injury. UpToDate. Available from www.uptodate.com/ contents/radiation-induced-lung-injury.

Montilla, N.A., Blas, M.P., López Santalla, M., and Martín Villa, J.M. 2004. Mucosal Immune System: A brief review. Inmunología. 23:207-216.

Napenas, J.J., Brennan, M.T., Bahrani-Mougeot, F.K., Fox, P.C., and Lockhart, P.B. 2007. Relationship between mucositis and changes in oral microflora during cancer chemotherapy. Oral Surg Oral Med Oral Pathol Oral Radiol Endod. 103(1):48-59. PMID: 17178494. doi: 10.1016/j.tripleo.2005.12.016.

Oliveira, A.L., de Souza, M., Carvalho-Dias, V.M., Ruiz, M.A., Silla, L., Tanaka, P.Y., Simoes, B.P., Trabasso, P., Seber, A., Lotfi, C.J., Zanichelli, M.A., Araujo, V.R., Godoy, C., Maiolino, A., Urakawa, P., Cunha, C.A., de Souza, C.A., Pasquini, R., and Nucci, M. 2007. Epidemiology of bacteremia and factors associated with multi-drug-resistant 
gram-negative bacteremia in hematopoietic stem cell transplant recipients. Bone Marrow Transplant. 39(12):775-781. PMID: 17438585. doi: 10.1038/sj. bmt.1705677.

Parkin, J., and Cohen, B. 2001. An overview of the immune system. Lancet. 357(9270):1777-1789. PMID: 11403834. doi: 10.1016/S0140-6736(00)04904-7.

Ram, S., Lewis, L.A., and Rice, P.A. 2010. Infections of people with complement deficiencies and patients who have undergone splenectomy. Clin Microbiol Rev. 23(4):740-780. PMID: 20930072. doi: 10.1128/ CMR.00048-09.

Ramphal, R. 2004. Changes in the etiology of bacteremia in febrile neutropenic patients and the susceptibilities of the currently isolated pathogens. Clin Infect Dis. 39(Suppl 1):S25-S31. PMID: 15250017. doi: $10.1086 / 383048$.

Renaud, C., and Englund, J.A. 2012. Antiviral therapy of respiratory viruses in haematopoietic stem cell transplant recipients. Antivir Ther. 17(1 Pt B):175-191. PMID: 22311587. doi: 10.3851/IMP2060.

Rijkers, G.T., Sanders, E.A., Breukels, M.A., and Zegers, B.J. 1998. Infant B cell responses to polysaccharide determinants. Vaccine. 16(14-15):13961400. PMID: 9711778.

Saag, M.S., Graybill, R.J., Larsen, R.A., Pappas, P.G., Perfect, J.R., Powderly, W.G., Sobel, J.D., and Dismukes, W.E. 2000. Practice guidelines for the management of cryptococcal disease. Infectious Diseases Society of America. Clin Infect Dis. 30(4):710-718. PMID: 10770733. doi: 10.1086/313757.

Shankar, G., and Cohen, D.A. 2001. Idiopathic pneumonia syndrome after bone marrow transplantation: The role of pre-transplant radiation conditioning and local cytokine dysregulation in promoting lung inflammation and fibrosis. Int J Exp Pathol. 82(2):101-113. PMID: 11454101.

Shankar, S.M., and Nania, J.J. 2007. Management of Pneumocystis jiroveci pneumonia in children receiving chemotherapy. Paediatr Drugs. 9(5):301-309. PMID: 17927302.
Silliman, C.C., Ambruso, D.R., and Boshkov, L.K. 2005. Transfusion-related acute lung injury. Blood. 105(6):2266-2273. PMID: 15572582. doi: 10.1182/ blood-2004-07-2929.

Soler-Palacin, P., Margareto, C., Llobet, P., Asensio, O., Hernandez, M., Caragol, I., and Espanol, T. 2007. Chronic granulomatous disease in pediatric patients: 25 years of experience. Allergol Immunopathol (Madr). 35(3):83-89. PMID: 17594870.

Sonis, S.T., Peterson, D.E., McGuire, D.B., and Williams, D.A. 2001. Prevention of mucositis in cancer patients. J Natl Cancer Inst Monogr. 29:1-2. PMID: 11694556.

Spitzer, T.R. 2001. Engraftment syndrome following hematopoietic stem cell transplantation. Bone Marrow Transplant. 27(9):893-898. PMID: 11436099. doi: 10.1038/sj.bmt.1703015.

Stokman, M.A., Spijkervet, F.K., Burlage, F.R., Dijkstra, P.U., Manson, W.L., de Vries, E.G., and Roodenburg, J.L. 2003. Oral mucositis and selective elimination of oral flora in head and neck cancer patients receiving radiotherapy: A doubleblind randomised clinical trial. Br J Cancer. 88(7):1012-1016. PMID: 12671696. doi: 10.1038/ sj.bjc. 6600824 .

Subbarayan, A., Colarusso, G., Hughes, S.M., Gennery, A.R., Slatter, M., Cant, A.J., and Arkwright, P.D. 2011. Clinical features that identify children with primary immunodeficiency diseases. Pediatrics. 127(5):810-816. PMID: 21482601. doi: 10.1542/ peds.2010-3680.

Vera-Llonch, M., Oster, G., Hagiwara, M., and Sonis, S. 2006. Oral mucositis in patients undergoing radiation treatment for head and neck carcinoma. Cancer. 106(2):329-336. PMID: 16342066. doi: 10.1002/cncr. 21622.

Yin, S., Powell, E.C., and Trainor, J.L. 2011. Serious bacterial infections in febrile outpatient pediatric kidney transplant recipients. Pediatr Infect Dis J. 30(2):136-140. PMID: 20729790. doi: 10.1097/INF. 0b013e3181f385bf. 